Article

\title{
Chemical Diversity of Headspace and Volatile Oil Composition of Two Brown Algae (Taonia atomaria and Padina pavonica) from the Adriatic Sea
}

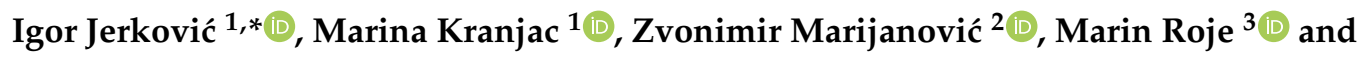 \\ Stela Jokić ${ }^{4}$ (i) \\ 1 Department of Organic Chemistry, Faculty of Chemistry and Technology, University of Split, Ruđera \\ Boškovića 35, 21000 Split, Croatia; mkranjac@ktf-split.hr \\ 2 Department of Food Technology and Biotechnology, Faculty of Chemistry and Technology, University of \\ Split, Ruđera Boškovića 35, 21000 Split, Croatia; zmarijanovic@ktf-split.hr \\ 3 Division of Organic Chemistry and Biochemistry, Ruđer Bosković Institute, Bijenička cesta 54, 10000 Zagreb, \\ Croatia; mroje@irb.hr \\ 4 Department of Process Engineering, Faculty of Food Technology, Josip Juraj Strossmayer University of \\ Osijek, Franje Kuhača 20, 31000 Osijek, Croatia; stela.jokic@ptfos.hr \\ * Correspondence: igor@ktf-split.hr; Tel.: +385-21-329-461
}

Received: 6 January 2019; Accepted: 27 January 2019; Published: 30 January 2019

\begin{abstract}
Two selected brown algae (Taonia atomaria and Padina pavonica from the family Dictyotaceae, order Dictyotales) growing in the same area (island Vis, central Adriatic Sea) were collected at the same time. Their phytochemical composition of the headspace volatile organic compounds (HS-VOCs; first time report) was determined by headspace solid-phase microextraction (HS-SPME). Hydrodistillation was applied for the isolation of their volatile oils (first report on T. atomaria volatile oil). The isolates were analyzed by gas chromatography (GC-FID) and mass spectrometry (GC-MS). The headspace and oil composition of T. atomaria were quite similar (containing germacrene $\mathrm{D}$, epi-bicyclosesquiphellandrene, $\beta$-cubebene and gleenol as the major compounds). However, P. pavonica headspace and oil composition differed significantly (dimethyl sulfide, octan-1-ol and octanal dominated in the headspace, while the oil contained mainly higher aliphatic alcohols, trans-phytol and pachydictol A). Performed research contributes to the knowledge of the algae chemical biodiversity and reports an array of different compounds (mainly sesquiterpenes, diterpenes and aliphatic compounds); many of them were identified in both algae for the first time. Identified VOCs with distinctive chemical structures could be useful for taxonomic studies of related algae.
\end{abstract}

Keywords: marine algae; headspace solid-phase microextraction (HS-SPME); hydrodistillation (HD); gas chromatography and mass spectrometry (GC-MS); sesquiterpenes; dimethyl sulfide; octan-1-ol

\section{Introduction}

Marine secondary metabolites possess outstanding structural and functional diversity related to their different metabolic pathways [1]. While the volatile organic compounds (VOCs) of terrestrial plants have attracted attention since antiquity, the VOCs of marine algae have been much less investigated. Therefore, the target of the present research are VOCs of two brown seaweeds from family Dictyotaceae, order Dictyotales: Taonia atomaria (Woodward) J. Agardh, 1848 and Padina pavonica (Linnaeus) Thivy, 1960.

T. atomaria (family Dictyotaceae, order Dictyotales, class Phaeophyceae) is a brown seaweed widespread in the Mediterranean Sea. Taondiol and atomaric acid, cyclised meroditerpenoids, were isolated from this alga collected in Canary Islands [2-4]. The chemical investigation of T. atomaria from 
the northern Adriatic Sea describes the identification of sesquiterpenes 4-cadinene, cadina-4(14),5-diene, (-)-germacrene D, axenol, (-)-cubebol and epi-cubebol from its petrol extract [5]. Two novel cyclised meroditerpenoids, atomarianones $\mathrm{A}$ and $\mathrm{B}$, were isolated from $\mathrm{MeOH} / \mathrm{CH}_{2} \mathrm{Cl}_{2}$ extract of T. atomaria collected at Serifos island in the Central Aegean Sea [6]. The freeze-dried alga T. atomaria, after exhaustive extraction with $\mathrm{CH}_{2} \mathrm{Cl}_{2} / \mathrm{MeOH}$, followed by chromatographic separations, afforded the compounds of tetraprenyl toluoquinone class, e.g., (Z)- and (E)-sargaquinone and sargaol [7]. T. atomaria sulfolipids were characterised by high contents of palmitic acid and the main constituents were sulfoquinovosyl-di-acylglycerol and sulfoquinovosyl acylglycerol [8]. The extracts of T. atomaria exhibited: (a) anticancer activity due the presence of algal sulfolipids [8], the compounds stypodiol [9] and stypoldione were determined as in vitro inhibitors of microtubule polymerization [10]; (b) antifungal activity due to taondiol presence [11]; (c) antibacterial activity due to algal sulfolipids [8]; (d) insecticidal activity related to isoepitaondiol [12]; (e) antiviral activity related to the algal sulfolipids [8]. In addition, the extracts of T. atomaria exhibited the best radical-scavenging activity (RSA) using DPPH and chemiluminescence (CL) tests in comparison to the extracts of the other 12 algal species from the island Crete, Greece and approached the activity of powerful antioxidant standards [13]. The isolated metabolites taondiol, isoepitaondiol, stypodiol, stypoldione, sargaquinone and sargaol were found to possess marked RSA. Recently, it was found that the surface metabolites of T. atomaria exhibit the ability to regulate epibiosis [14].

P. pavonica belongs to the family Dictyotaceae, order Dictyotales, class Phaeophyceae and is widespread in the Adriatic Sea. The characteristic brown algal polysaccharides alginates and laminarans were found in P. pavonica [15]. Chlorophyll $C_{1}$ and $C_{2}$, fucoxanthin, fucoxanthol, flavoxanthin and diatoxanthin were the most typical pigments in P. pavonica [16]. The chemical composition of this seaweed from the southern Adriatic Sea was investigated [17] and 12 sterols were identified in $\mathrm{CH}_{2} \mathrm{Cl}_{2} / \mathrm{MeOH}$ extract, the main ones being cholesterol and fucosterol. The most abundant fatty acid was palmitic acid, followed by oleic acid and myristic acid. The toluene extract was subjected to 4-h simultaneous distillation-extraction (SDE; [17]); and in the volatile fraction, aromatic esters, benzyl alcohol, benzaldehyde, and free fatty acids dominated with low concentrations of terpenoids, phenols and sulfur containing compounds. P. pavonica collected from Red sea coast, Egypt was subjected to direct SDE and bis-2-ethylhexyl phthalate was the major compound. P. pavonica extracts exhibited: (a) antimicrobial activity [17,18]; (b) antifungal activity [19,20]; (c) antioxidant activity [20] that may be due to phenolic compounds; (d) cytotoxicity against KB cells [21]; oxysterol and hydroperoxy-24 vinyl-24 cholesterol were identified as being responsible for this activity; and (e) antitumor activity against lung (H460) and liver (HepG2) human carcinoma cell lines [22] due to xenicane diterpenes 18,19-epoxyxenic-19-methoxy-18-hydroxy-4-acetoxy-6,9,13-triene and 18,19-epoxyxenic-18,19-dimethoxy-4-hydroxy-6,9,13-triene.

Although there are few previous reports on the high-molecular VOCs from T. atomaria $[5,23]$ and P. pavonica $[17,22,24]$, there are no reports on the headspace composition of these algae. Headspace solid-phase microextraction (HS-SPME) is the appropriate method for the research of low-molecular and highly-volatile headspace compounds, while hydrodistillation (HD) is an adequate method for isolating volatile and less-volatile compounds. It is well known that the headspace composition is different form the hydrodistillate/extract composition, and certain lower molecular compounds can be found only in the headspace. Among them, chemotaxonomic markers, allelochemicals, defensive compounds, attractants, or alarming pheromones can be found that are participating in chemical communications in marine ecosystems or playing ecological roles. In addition, there is no data on T. atomaria direct hydrodistillate (HD) composition, there are only reports on EtOAc and petroleum extract composition containing several sesquiterpenes among other constituents. Therefore, the goals of the present study on two selected brown algae growing in the same area (island Vis, Adriatic Sea) and collected at the same time were to: (a) determine the phytochemical percentage (\%) composition of the headspace VOCs (first time report) by HS-SPME followed by gas chromatography and mass spectrometry (GC-FID; GC-MS) analysis; (b) determine by GC-FID and GC-MS the chemical 
composition of their volatile oils isolated by hydrodistillation (first report on T. atomaria volatile oil); (c) compare the results of the corresponding headspace and volatile oil chemical composition; (d) discuss the obtained results in comparison to the literature data, particularly regarding the extracts composition or the algal volatile oils from different geographic areas; and (e) indicate possible biosynthetic formation pathways of the major identified compounds according to the literature data.

\section{Results and Discussion}

In order to investigate the chemical diversity of the headspace and volatile oil composition from two brown algae of the family Dictyotaceae, order Dictyotales collected from the Adriatic Sea from the same area (island Vis, Croatia), two complementary methods were used: headspace solid-phase microextraction (HS-SPME) and hydrodistillation (HD) followed by gas chromatography and mass spectrometry (GC-FID; GC-MS) analysis. In order to avoid the changes that could occur in VOCs from the native samples after a long time of collection or drying, both algae were investigated as fresh samples. Two fibres of different polarity were used for HS-SPME (Polydimethylsiloxane/Divinylbenzene (PDMS/DVB) and Divinylbenzene/Carboxen/Polydimethylsiloxane (DVB/CAR/PDMS)) to obtain more complete chemical profiles. The results pointed out striking differences between the chemical profiles for the headspace and volatile oil of the same algae (depending on the compounds molecular mass and volatility). It should be taken into consideration that the headspace composition does not reflect the composition percentage of the sample (only of the headspace) and hydrodistillation is not an adequate method for the isolation of water-soluble, high-molecular compounds and less volatile compounds such as diterpenes.

\subsection{Headspace and Volatile Oil Composition of T. atomaria}

The headspace of T. atomaria is dominated with germacrene D (32.06\% (PDMS/DVB fibre); $27.89 \%$ (DVB/CAR/PDMS fibre)) and sesquiterpene bicyclic hydrocarbons of cadinane type skeleton epi-bicyclosesquiphellandrene $(27.49 \% ; 25.13 \%)$ followed by cadina-3,5-diene $(2.45 \% ; 3.60 \%)$, trans-cadina-1(6),4-diene $(1.21 \% ; 2.39 \%)$ and zonarene $(2.25 \% ; 2.53 \%)$. An array of other cadinane type structures with minor percentages were identified (Table 1). Another abundant compound with tricyclic sesquiterpene skeleton of cubebane type was $\beta$-cubebene $(12.80 \% ; 10.74 \%)$ with a minor percentage of its isomer $\alpha$-cubebene $(2.53 \% ; 2.48 \%)$. In addition, axane type (bicyclic spiro[4,5]decane) sesquiterpene alcohol gleenol was found among major constituents $(9.68 \% ; 11.02 \%)$. Several compounds were found as minor constituents exclusively in the headspace (Table 1) such as: dimethyl sulfide, 2-ethylhex-1-yl acetate, bornyl acetate, $\gamma$-elemene, cyclosativene, $\alpha$-ylangene, and $\beta$-patchoulene. The headspace composition of this algae is reported for the first time.

Table 1. Headspace and volatile oil composition of T. atomaria (RI from the literature used for identifying the compounds).

\begin{tabular}{|c|c|c|c|c|c|}
\hline \multirow[b]{2}{*}{ No. } & \multirow{2}{*}{ Compound } & \multirow[b]{2}{*}{ RI } & \multicolumn{3}{|c|}{ Area Percentages (\%) } \\
\hline & & & $\begin{array}{c}\text { HS-SPME } \\
(\text { PDMS/DVB) } \pm \text { SD }\end{array}$ & $\begin{array}{c}\text { HS-SPME } \\
(\mathrm{DVB} / \mathrm{CAR} / \mathrm{PDMS}) \pm \mathrm{SD}\end{array}$ & $\mathrm{HD} \pm \mathrm{SD}$ \\
\hline 1 & Dimethyl sulfide $\mathrm{S}$ & 523 & $0.06 \pm 0.01$ & $0.02 \pm 0.01$ & - \\
\hline 2 & $p$-Xylene ${ }^{\mathrm{S}}$ & 870 & - & - & $0.01 \pm 0.01$ \\
\hline 3 & 2-Ethyl-1-hexyl acetate & 1151 & $0.03 \pm 0.01$ & $0.03 \pm 0.00$ & - \\
\hline 4 & Albene & 1160 & - & - & $0.01 \pm 0.00$ \\
\hline 5 & Bornyl acetate $\mathrm{S}$ & 1286 & - & $0.01 \pm 0.00$ & - \\
\hline 6 & $\gamma$-Elemene & 1341 & $0.06 \pm 0.01$ & $0.09 \pm 0.01$ & - \\
\hline 7 & $\alpha$-Cubebene ${ }^{S}$ & 1353 & $2.53 \pm 0.06$ & $2.48 \pm 0.05$ & $0.16 \pm 0.01$ \\
\hline 8 & Cyclosativene $^{\mathrm{S}}$ & 1368 & $0.01 \pm 0.00$ & $0.01 \pm 0.00$ & - \\
\hline 9 & $\alpha$-Ylangene & 1374 & $0.02 \pm 0.00$ & $0.06 \pm 0.01$ & - \\
\hline 10 & $\alpha$-Copaene ${ }^{S}$ & 1379 & $0.04 \pm 0.01$ & $0.12 \pm 0.02$ & $0.02 \pm 0.00$ \\
\hline
\end{tabular}


Table 1. Cont.

\begin{tabular}{|c|c|c|c|c|c|}
\hline \multirow[b]{2}{*}{ No. } & \multirow{2}{*}{ Compound } & \multirow{2}{*}{$\mathbf{R I}$} & \multicolumn{3}{|c|}{ Area Percentages (\%) } \\
\hline & & & $\begin{array}{c}\text { HS-SPME } \\
(\text { PDMS/DVB) } \pm \text { SD }\end{array}$ & $\begin{array}{c}\text { HS-SPME } \\
(\mathrm{DVB} / \mathrm{CAR} / \mathrm{PDMS}) \pm \mathrm{SD}\end{array}$ & $\mathrm{HD} \pm \mathrm{SD}$ \\
\hline 11 & $\beta$-Patchoulene & 1383 & $0.02 \pm 0.00$ & $0.02 \pm 0.01$ & - \\
\hline 12 & $\beta$-Bourbonene & 1387 & $0.71 \pm 0.04$ & $0.63 \pm 0.02$ & $0.49 \pm 0.01$ \\
\hline 13 & $\beta$-Cubebene & 1393 & $12.80 \pm 0.53$ & $10.74 \pm 0.01$ & $6.10 \pm 0.25$ \\
\hline 14 & $\beta$-Ylangene & 1421 & $0.50 \pm 0.03$ & $0.61 \pm 0.04$ & $0.17 \pm 0.01$ \\
\hline 15 & $\beta$-Copaene & 1432 & $0.31 \pm 0.02$ & $0.45 \pm 0.03$ & $0.12 \pm 0.01$ \\
\hline 16 & trans- $\alpha$-Bergamotene & 1437 & - & - & $0.01 \pm 0.00$ \\
\hline 17 & Aromandendrene $^{\mathrm{S}}$ & 1442 & $0.01 \pm 0.00$ & $0.02 \pm 0.01$ & - \\
\hline 18 & Isogermacrene D & 1447 & $0.10 \pm 0.02$ & $0.13 \pm 0.02$ & $0.03 \pm 0.01$ \\
\hline 19 & Cadina-3,5-diene & 1454 & $2.45 \pm 0.07$ & $3.60 \pm 0.02$ & $0.39 \pm 0.02$ \\
\hline 20 & $(E)-\beta$-Farnesene ${ }^{S}$ & 1461 & $0.04 \pm 0.00$ & - & $0.02 \pm 0.00$ \\
\hline 21 & cis-Muurola-4(15),5-diene & 1467 & - & - & $0.07 \pm 0.01$ \\
\hline 22 & $\alpha$-Muurolene & 1470 & - & - & $0.01 \pm 0.00$ \\
\hline 23 & Alloaromadendrene $\mathrm{S}$ & 1464 & $0.13 \pm 0.02$ & $0.26 \pm 0.03$ & $0.19 \pm 0.02$ \\
\hline 24 & $\gamma$-Gurjunene ${ }^{\mathrm{s}}$ & 1473 & - & - & $0.11 \pm 0.01$ \\
\hline 25 & trans-Cadina-1(6),4-diene & 1477 & $1.21 \pm 0.02$ & $2.39 \pm 0.04$ & - \\
\hline 26 & $\alpha$-Amorphene & 1479 & - & - & $0.17 \pm 0.02$ \\
\hline 27 & 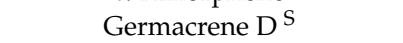 & 1486 & $32.06 \pm 2.16$ & $27.89 \pm 2.00$ & $22.24 \pm 1.92$ \\
\hline 28 & $\gamma$-Muurolene & 1487 & - & - & $0.11 \pm 0.02$ \\
\hline 29 & epi-Bicyclosesquiphellandrene & 1496 & $27.49 \pm 2.03$ & $25.13 \pm 2.20$ & $20.83 \pm 1.90$ \\
\hline 30 & $\gamma$-Amorphene & 1495 & - & - & $2.10 \pm 0.05$ \\
\hline 31 & Bicyclogermacrene & 1498 & $0.87 \pm 0.05$ & $0.63 \pm 0.03$ & - \\
\hline 32 & Epizonarene & 1500 & - & $0.66 \pm 0.08$ & - \\
\hline 33 & $\alpha$-Muurolene & 1502 & $0.27 \pm 0.02$ & $0.57 \pm 0.06$ & $0.33 \pm 0.04$ \\
\hline 34 & $\beta$-Cadinene & 1509 & $0.14 \pm 0.01$ & $0.22 \pm 0.03$ & - \\
\hline 35 & Tridecanal $^{\mathrm{S}}$ & 1511 & $0.05 \pm 0.01$ & $0.01 \pm 0.00$ & $0.08 \pm 0.01$ \\
\hline 36 & $\gamma$-Cadinene & 1517 & $0.40 \pm 0.02$ & $0.97 \pm 0.05$ & $2.14 \pm 0.09$ \\
\hline 37 & Cubebol & 1519 & $1.08 \pm 0.02$ & $1.10 \pm 0.01$ & - \\
\hline 38 & $\delta$-Cadinene ${ }^{\mathrm{S}}$ & 1527 & $1.13 \pm 0.03$ & $2.14 \pm 0.05$ & $1.09 \pm 0.02$ \\
\hline 39 & Zonarene & 1529 & $2.25 \pm 0.05$ & $2.53 \pm 0.08$ & $1.45 \pm 0.05$ \\
\hline 40 & trans-Cadina-1,4-diene & 1536 & $0.46 \pm 0.02$ & $0.83 \pm 0.04$ & $0.24 \pm 0.01$ \\
\hline 41 & $\alpha$-Cadinene & 1541 & $0.18 \pm 0.01$ & $0.49 \pm 0.03$ & $0.03 \pm 0.01$ \\
\hline 42 & $\alpha$-Calacorene & 1546 & $0.01 \pm 0.00$ & $0.08 \pm 0.01$ & - \\
\hline 43 & Gleenol & 1590 & $9.68 \pm 0.80$ & $11.02 \pm 0.70$ & $15.35 \pm 0.95$ \\
\hline 44 & Junenol & 1518 & - & - & $0.17 \pm 0.02$ \\
\hline 45 & Di-epi-1,10-cubenol & 1629 & - & - & $0.54 \pm 0.01$ \\
\hline 46 & T-Cadinol & 1646 & $0.31 \pm 0.05$ & $0.39 \pm 0.04$ & $1.59 \pm 0.05$ \\
\hline 47 & $\alpha$-Muurolol (Torreyol) & 1648 & - & - & $0.49 \pm 0.05$ \\
\hline 48 & $\delta$-Cadinol & 1654 & - & - & $0.25 \pm 0.02$ \\
\hline 49 & $\alpha$-Cadinol & 1659 & $0.03 \pm 0.00$ & $0.01 \pm 0.00$ & $1.45 \pm 0.09$ \\
\hline 50 & Pentadecanal & 1714 & $0.03 \pm 0.00$ & $0.01 \pm 0.00$ & $0.16 \pm 0.01$ \\
\hline 51 & 4,10(14)-Cadinadien- $8-\beta-\mathrm{ol}$ * & 1784 & $1.03 \pm 0.05$ & $0.84 \pm 0.08$ & $1.94 \pm 0.09$ \\
\hline 52 & Diisobutyl phthalate $\mathrm{s}$ & 1870 & $0.01 \pm 0.00$ & $0.09 \pm 0.01$ & $4.23 \pm 0.09$ \\
\hline 53 & Isocembrol (Thunbergol) & 2040 & - & - & $0.73 \pm 0.02$ \\
\hline 54 & Pachydictyol A & 2123 & - & - & $3.26 \pm 0.06$ \\
\hline 55 & Cembra-4,7,11,15-tetraen-3-ol * & 2226 & - & - & $2.46 \pm 0.05$ \\
\hline
\end{tabular}

RI retention indices relative to $\mathrm{C}_{9}-\mathrm{C}_{25}$ alkanes, ${ }^{*}$ tentatively identified, ${ }^{\mathrm{S}}$ identification confirmed with standard compound, SD standard deviation.

Germacrene D (22.24\%), epi-bicyclosesquiphellandrene (20.83\%) and gleenol (15.35\%) were dominant compounds in the hydrodistillate as well. Smaller percentages of other cadinane types as well as selinane type sesquiterpenes were found (Table 1). However, in the distillate, several higher molecular compounds were found (that were not present in the headspace) such as diterpenes (pachydictyol A, cembra-4,7,11,15-tetraen-3-ol and isocembrol), higher aliphatic compounds (e.g., tridecanal or pentadecanal), sesquiterpenes (trans- $\alpha$-bergamotene, $\alpha$-amorphene, junenol, di-epi-1,10-cubenol, or $\delta$-cadinol), trisnorsesquiterpene albene and $p$-xylene.

The major VOCs found in the headspace and oil are known to exhibit different biological activities. Germacrene D is involved in plant-insect interaction, acting as a pheromone on receptor neurones [25] and is also an important deterrent and insecticidal agent against different parasites such as mosquitos, aphids and ticks [26,27]. Germacrene D could be considered responsible for the cytotoxic activity of 
Kundmannia sicula (L.) D.C. essential oil being the main compound present in the oil (81.2\%) [28]. This is in agreement with the results reported by Setzer et al. [29] where germacrene D resulted active against human breast adenocarcinoma (MDA-MB 231 and MCF-7), human ductal carcinoma (Hs 578T) and human hepatocellular carcinoma (Hep G2). Epi-bicyclosesquiphellandrene could be connected with antidermatophytic activity [30]. Gleenol exhibited the following biological activities: termiticidal, antihelminitic and growth regulation effects on plant seeds [31].

In comparison with previous research of T. atomaria, it is only possible to partially compare the results, since different extracts were investigated previously (not obtained by HS-SPME or HD, but with other methods targeting non-volatile compounds). The extracts mostly contained high-molecular compounds and researches were directed toward the isolation of individual components, not toward obtaining full chemical profiles. The compounds 4-cadinene, cadinane-4(14),5-diene, (-)-germacrene D, axenol, (-)-cubebol, and 4-epi-cubebol were previously identified in petroleum extract (after chromatographic purification) of dried T. atomaria collected in the North Adriatic sea [5]. Therefore, partial similarity with current research data is notable (the presence of cadinane type sesquiterpenes). Less similarity was noticed with respect to recent research on $\mathrm{MeOH} / \mathrm{CH}_{2} \mathrm{Cl}_{2}$ extract of T. atomaria [14]. Germacra-4(15),5,10(14)-trien-9-ol was identified together with five other sesquiterpenes (-)-gleenol, $\alpha$-cadinol methyl ether, (-)-trans-calamenene, $(1 S, 5 E, 7 S)$ 1-acetoxygermacra-4(15),5,10(14)-triene, and 4-peroxymuurol-5-ene. Moreover, two lipidic compounds, polyunsaturated fatty acid, (5Z,8Z,11Z,14Z,17Z)-eicosa-5,8,11,14,17-pentaenoic acid, and glycerol derivative, sn-3-O-(geranylgeranyl)glycerol were also isolated. However, in comparison with the mentioned results of other researchers, current research presents a complete chemical profile of the headspace and volatile oil composition, providing new data: epi-cyclosesquiphellandrene as a dominant compound was found for the first time in T. atomaria as well as numerous other sesquiterpenes with lower abundance (Table 1), not previously reported.

\subsection{Headspace and Volatile Oil Composition of P. pavonica}

A total of 17 compounds were found in the headspace of P. pavonica. Aliphatic fatty alcohol octan-1-ol was a dominant constituent (37.73\%; 38.60\%) along with its oxygenated derivative octanal $(9.63 \% ; 7.98 \%)$. Another major constituent was dimethyl sulfide (DMS; 18.27\%; 26.37\%). All three compounds were reported for the first time in this alga (only in the headspace). However, $\mathrm{C}_{8}$-hydrocarbons were previously found in various marine algae [32,33], usually (3Z,5E)-octa-1,3,5-triene (fucoserratene), but octan-1-ol was not found previously in such high headspace abundance. On the other hand, octan-1-ol was found in raw water taken during Synura uvella algal blooms after adsorption on Tenax and thermal desorption [34]. DMS, a highly-volatile organosulfur compound, serves as a chemoattractant for phytoplankton, bacteria, zooplankton, fish, and sea birds [35]. Three sulfur-containing compounds (methylethyl disulfide, diethyl disulfide and benzothiazole) were previously identified in toluene extract of $P$. pavonica that was subjected to 4-h simultaneous distillation-extraction (SDE) [17], but DMS was not present. Neither was it found after direct SDE of this algae [22]. Therefore, in accordance with our previous paper [32], we can use HS-SPME as the appropriate method for monitoring DMS presence. $(E)$ - $\beta$-farnesene $(7.92 \% ; 6.28 \%)$ was a major sesquiterpene, followed by $\beta$-bisabolene, $\alpha$-farnesene and cis- and trans-calamenene (Table 2). Smaller percentages of dictyopterene A and dictyopterene $\mathrm{D}^{\prime}$ were found. Benzaldehyde was found as a minor headspace constituent, and was also identified after SDE of P. pavonica toluene extract [17]. 
Table 2. Headspace and volatile oil composition of P. pavonica.

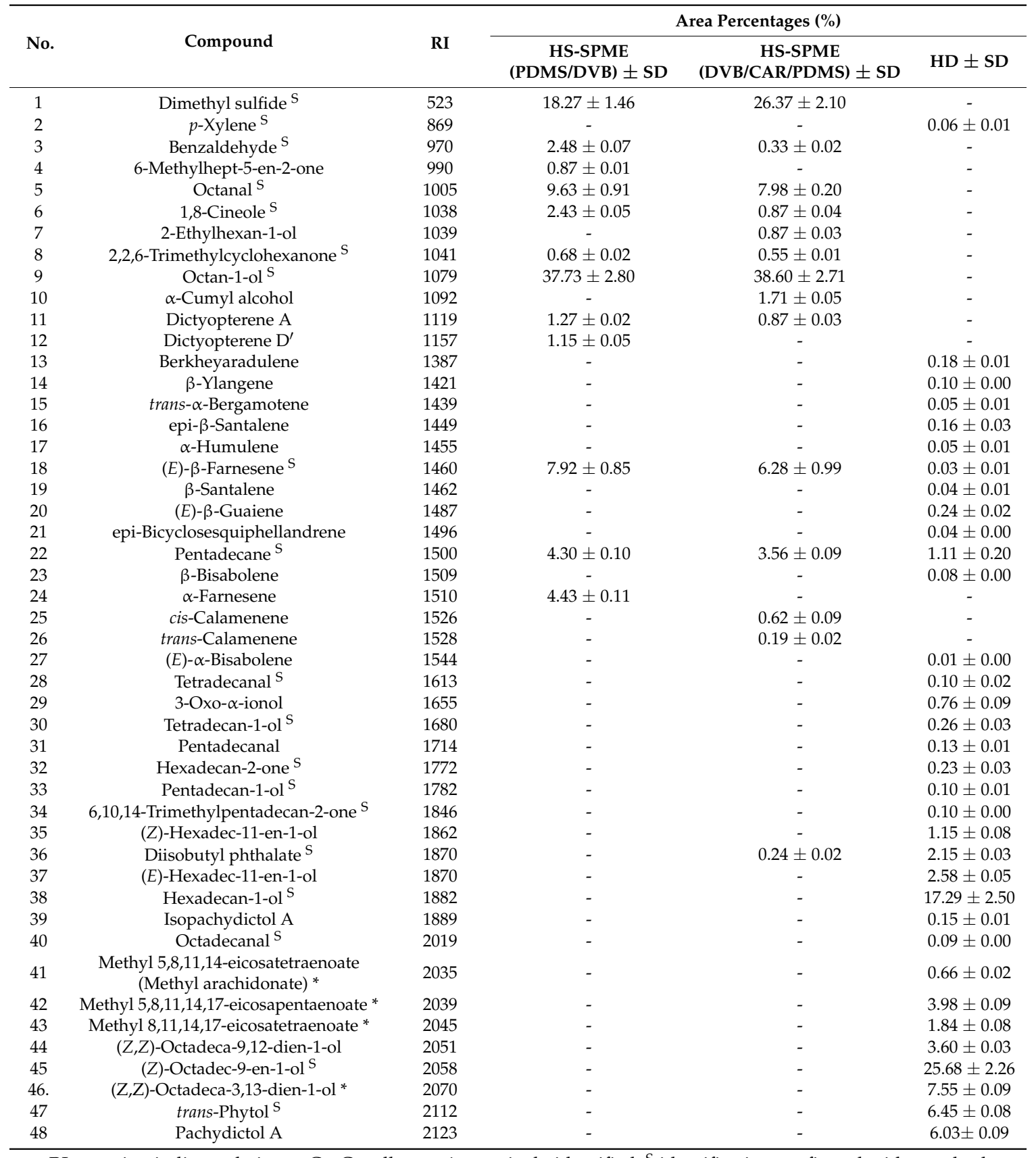

RI retention indices relative to $\mathrm{C}_{9}-\mathrm{C}_{25}$ alkanes, ${ }^{*}$ tentatively identified, ${ }^{\mathrm{S}}$ identification confirmed with standard compound, $\mathrm{SD}$ standard deviation.

The chemical profiles of P. pavonica hydrodistillate and headspace are significantly different containing only three common compounds $((E)-\beta$-farnesene, pentadecane and diisobutyl phthalate), but with different abundance (Table 2). The major oil compounds were higher aliphatic alcohols: (Z)-octadec-9-en-1-ol (25.68\%), hexadecan-1-ol (17.29\%), and (Z,Z)-octadeca-3,13-dien-1-ol (7.55\%) along with minor percentages of tetradecan-1-ol, pentadecanal, hexadecan-2-one, pentadecan-1-ol, (Z)-hexadec-11-en-1-ol, (E)-hexadec-11-en-1-ol, octadecanal, and (Z,Z)-octadeca-9,12-dien-1-ol. Higher aliphatic esters were found as minor constituents such as: methyl 5,8,11,14-eicosatetraenoate, methyl 5,8,11,14,17-eicosapentaenoate and methyl 8,11,14,17-eicosatetraenoate. Diterpene alcohols trans-phytol (6.45\%) and pachydictol A (6.03\%) were among the relevant compounds in the oil with a minor abundance of isopachydictol A. Several sesquiterpenes were present: trans- $\alpha$-bergamotene, 
epi- $\beta$-santalene, $\alpha$-humulene, $\beta$-santalene, $(E)$ - $\beta$-guaiene, $\beta$-bisabolene, and $(E)-\alpha$-bisabolene. These sesquiterpenes as well as pachydictol $A$ and isopachydictyol $A$ were for the first time found in P. pavonica. In comparison with previous papers on VOCs, from this alga, only partial similarity is observed. Namely, the major compound of SDE isolate [22] was bis-2-ethylhexyl phtalate (40.22\%), while in the current research, diisobutyl phthalate was found as a minor constituent. Fatty esters such as methyl eicosa-5,8,11,14-tetraenoate, methyl eicosa-5,8,11,14,17-tetraenoate and diterpene phytol were found previously in this alga [22] as well in the current research. The presence of free fatty acids was also reported [22]. Sesquiterpene compounds $\beta$-cubebene, germacrene $\mathrm{D}$ and santalol were previously detected in P. pavonica SDE isolate [22], but not in the present research where several other sesquiterpenes were found (Table 2). P. pavonica toluene extract subjected to 4-h SDE [17] provided esters benzyl acetate and benzyl formate as the major compounds. Besides the esters of benzoic acid, significant concentrations of their biogenetic precursors benzaldehyde and benzyl alcohol were found, but they were not identified in the isolated oil. Therefore, the assumption that these compounds can serve as biomarkers for these algae [17] is questionable. In addition, low concentrations of the common marine algal terpene dihydroactinidiolide and $\mathrm{C}_{13}$-norisoprenoid $\beta$-ionone were found previously, and in the obtained oil, diterpenes isopachydictyol $\mathrm{A}$ and pachydictol $\mathrm{A}$ as well as $\mathrm{C}_{13}$-norisoprenoid 3-oxo- $\alpha$-ionol were present.

\subsection{Possible Biosynthetic Origin of the Major Identified VOCs}

Sesquiterpenes, dominant in the T. atomaria headspace and volatile oil, are $\mathrm{C}_{15}$-compounds containing the assembly of three isoprenoid units. The large number of sesquiterpenoid carbon skeletons arises from the common precursor, farnesyl pyrophosphate (FPP), by various modes of cyclizations usually followed by skeletal rearrangement (Figure 1).

Selinane and cadinane are two main types of sesquiterpenes reported in brown algae [36]. According to the currently accepted hypotheses, in addition to farnesyl pyrophosphate (FPP), neryl pyrophosphate (NPP) may be a precursor in sesquiterpenes formation (Figure 1). It can be assumed [37] that in the cyclisation process (after pyrophosphate (PP) loss) germacrenyl cations A and B are formed, and after hydride migration, cations $C$ and D are formed (Figure 1). For the biosynthesis of cadinene-type sesquiterpenes, two alternative pathways were suggested [38]. The primarily formed cation A may be transformed to cation $C$ and after deprotonated to germacrene $\mathrm{D}(\mathrm{lb})$. The subsequent change from cis- structure to trans- $1 \mathrm{~b}$ is crucial for the formation of cadinane type sesquiterpenes (with $\mathrm{Z}$ double bond in the ring) followed by protonation and rearrangement to cation D. As an alternative, NPP may serve as a substrate for cadinene-type sesquiterpene biosynthesis. In this case, the cyclization to the cadinanes would proceed via cations B and D. Moreover, it can be assumed that germacrene $\mathrm{D}$ and germacrenyl cation $\mathrm{D}$ are the biosynthetic precursors of the major isolated sesquiterpenes from T. atomaria. Major sesquiterpenes of this alga with cadinane skeleton that could be derived from germacrene $\mathrm{D}$ were (Figure 1): cadina-1(6),4-diene, $\delta$-cadinene, cadina-3,5-diene, 4-epi-bicyclosesquiphellandrene; ylangene; cubebol, $\beta$-cubebene, $\alpha$-cubebene, zonarene, and gleenol. Bicyclogermacrene is probably derived from germacrenyl cation $C$.

Dimethyl sulfide (DMS), a major compound of the P. padina headspace, results from an enzymatic decomposition of dimethyl- $\beta$-propiothetin [33], a metabolite of methionine that is fairly widespread in marine plants. Formed dimethylsulfoniopropionate (DMSP), a tertiary sulfonium compound, is the precursor of DMS. Recently, the algal enzyme responsible for the formation of DMS from DMSP was found and characterised in alga Emiliania huxleyi [39].

In general, the overall mechanism of enzymatic lipid degradation is identical in terrestrial plants [40] and algae [41]. The enzyme cascade is initiated by activated phospholipase, followed by lipoxygenase and hydroperoxide lyase. However, the particular enzymes are highly species- and sometimes even strain-specific [41], and this can explain the large biodiversity of lipid degradation VOCs (e.g., carbonyl compounds, alcohols, and hydrocarbons). Marine algae contain unsaturated fatty acids, and they can produce $C_{18}, C_{20}$ and $C_{22}$ fatty acid hydroperoxides. Following the 
general concept of lipid peroxidation, and subsequent oxidative cleavage of the carbon skeleton, the biosynthesis of $\mathrm{C}_{8}$-hydrocarbons from P. pavonica could start from the polyunsaturated fatty acid substrate that could be activated [42] either by 9-lipoxygenase or by 12-lipoxygenase producing 9- or 12-hydroperoxides that further cleave oxidatively to produce $\mathrm{C}_{8}$-compounds. Octanal could originate from $\omega 9$ mono-unsaturated fatty acids (MUFAs) and also from $\omega 6$ poly-unsaturated fatty acids (PUFAs) such as linoleic acid [43].

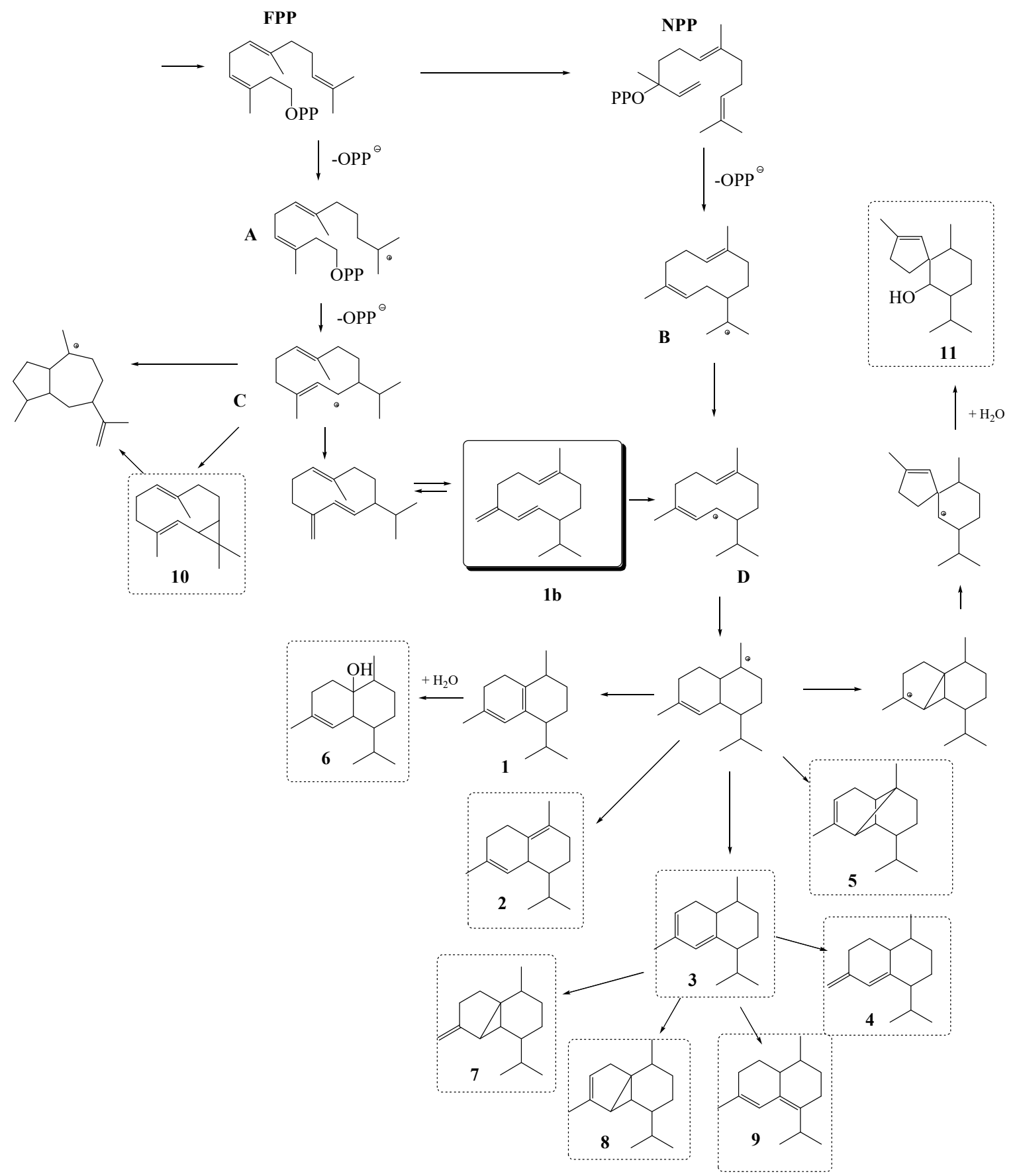

Figure 1. Possible biosynthetic correlations $[37,38]$ among the main identified compounds in T. atomaria: FPP_farnesyl pyrophosphate; NPP_neryl pyrophosphate; germacreny cations (A, B, C and D); 1: cadina-1(6),4-diene; 2 : $\delta$-cadinene; 3: cadina-3,5-diene; 4: epi-bicyclosesquiphellandrene; 5: ylangene; 6: cubebol; 7: $\beta$-cubebene; 8: $\alpha$-cubebene; 9: zonarene; 10: bicyclogermacrene; 11: gleenol; 1 b: germacrene $\mathrm{D}$. 


\section{Materials and Methods}

The samples of two brown algae Taonia atomaria (Woodward) J. Agardh, 1848 and Padina pavonica (Linnaeus) Thivy, 1960) were collected in the middle of the Adriatic Sea, in island Vis bay near Prirovo peninsula in May 2018. The geographical coordinates of the sampling were: $43^{\circ} 3^{\prime} 47^{\prime \prime} \mathrm{N}, 16^{\circ} 11^{\prime} 15^{\prime \prime} \mathrm{E}$ (P. pavonica) and $43^{\circ} 3^{\prime} 44^{\prime \prime} \mathrm{N}, 16^{\circ} 11^{\prime} 16^{\prime \prime} \mathrm{E}$ (T. atomaria). Single point sample collection provided representative samples. The algae were collected from depths of $1 \mathrm{~m}$ with the sea temperature at $17^{\circ} \mathrm{C}$. The samples were separately collected and placed in air-tight plastic bags containing surrounding seawater and were immediately transported to the laboratory. The samples were kept in the dark at $4{ }^{\circ} \mathrm{C}$, and the extractions were performed within $48 \mathrm{~h}$ of the collection. Before headspace solid-phase microextraction (HS-SPME), each sample was separately cut into small pieces and the excess seawater was removed by placing it between the filter paper layers for $2 \mathrm{~min}$ (the seawater was not removed completely) as was done in previous research [32].

\subsection{Headspace Solid-Phase Microextraction (HS-SPME)}

Headspace solid-phase microextraction (HS-SPME) was performed with a manual SPME holder using two fibres covered with PDMS/DVB (Polydimethylsiloxane/Divinylbenzene) or DVB/CAR/PDMS (Divinylbenzene/Carboxen/Polydimethylsiloxane) obtained from Supelco Co. (Bellefonte, PA, USA). The fibres were conditioned prior to the extraction according to the instructions by Supelco Co. For HS-SPME, prepared samples $(1 \mathrm{~g})$ were placed separately in $5 \mathrm{~mL}$ glass vials and hermetically sealed with PTFE/silicone septa. The vials were maintained in a water bath at $60^{\circ} \mathrm{C}$ during equilibration (15 min) and HS-SPME (45 min). After the sampling, the SPME fibre was withdrawn into the needle, removed from the vial, and inserted into the injector $\left(250{ }^{\circ} \mathrm{C}\right)$ of $\mathrm{GC}-\mathrm{FID}$ and GC-MS for 6 min where the extracted volatiles were thermally desorbed directly to the GC column. The procedure was similar as in previous paper [32]. HS-SPME was done in triplicate for each alga.

\subsection{Hydrodistillation (HD)}

Hydrodistillation was performed in a modified Clevenger apparatus for $2 \mathrm{~h}$ with the use of $1 \mathrm{~mL}$ of solvent trap (pentane:diethyl ether 1:2 v/v). The prepared samples (10 g; cut into small pieces) were used separately for the hydrodistillation. The volatile oil dissolved in the solvent trap was removed with a pipette, passed through the layer of $\mathrm{MgSO}_{4}$ in a small glass funnel and carefully concentrated by the slow flow of nitrogen until the volume of $0.2 \mathrm{~mL}$. The hydrodistillation for each sample was performed in triplicate. One microlitre was used for GC-FID and GC-MS analyses.

\subsection{Gas Chromatography and Mass Spectrometry (GC-MS) Analyses}

Gas chromatography and mass spectrometry (GC-MS) analyses were done on an Agilent Technologies (Palo Alto, CA, USA) gas chromatograph model 7890A equipped with a flame ionization detector (FID) and a HP-5MS capillary column (5\% phenyl-methylpolysiloxane, Agilent J and W). The GC conditions were the same as described previously [32]. In brief, the oven temperature was set up isothermally at $70{ }^{\circ} \mathrm{C}$ for $2 \mathrm{~min}$, then increased from $70-200{ }^{\circ} \mathrm{C}$ at $3^{\circ} \mathrm{C} \cdot \mathrm{min}^{-1}$, and held isothermally at $200{ }^{\circ} \mathrm{C}$ for $15 \mathrm{~min}$; the carrier gas was helium $\left(\mathrm{He} 1.0 \mathrm{~mL} \cdot \mathrm{min}^{-1}\right)$. The GC-MS analyses were done on an Agilent Technologies (Palo Alto, CA, USA) gas chromatograph model 7820A equipped with a mass selective detector (MSD) model 5977E (Agilent Technologies) and HP-5MS capillary column, under the same conditions as for the GC-FID analysis. The MSD (EI mode) was operated at $70 \mathrm{eV}$, and the mass range was 30-300 amu.

The identification of VOCs was based on the comparison of their retention indices (RI), determined relative to the retention times of $n$-alkanes $\left(C_{9}-C_{25}\right)$, with those reported in the literature (National Institute of Standards and Technology [44]) and their mass spectra with the spectra from Wiley 9 (Wiley, New York, NY, USA) and NIST 14 (D-Gaithersburg) mass spectral libraries. The percentage composition of the samples was computed from the GC peak areas using the normalization method 
(without correction factors). The average component percentages in Tables 1 and 2 were calculated from GC-FID and GC-MS analyses.

\section{Conclusions}

HS-SPME and hydrodistillation were adequate and complementary methods for the research of headspace and volatile oil composition of T. atomaria and P. pavonica. Although these two seaweed species belong to the same botanical family and order, and were collected from the same area at the same time, significant diversity in their VOCs composition was found. The headspace and oil composition of T. atomaria were quite similar (containing germacrene D, epi-bicyclosesquiphellandrene, $\beta$-cubebene and gleenol as the major compounds). However, the headspace and oil composition of P. pavonica differed significantly (dimethyl sulfide, octan-1-ol and octanal dominated in the headspace, while the oil contained mainly higher aliphatic alcohols, trans-phytol and pachdityol A). The current research contributed to the knowledge of algae chemical biodiversity since the obtained chemical profiles reveal an array of different compounds (mainly sesquiterpenes, diterpenes and aliphatic compounds); many of them were identified in both algae for the first time. Identified VOCs with distinctive chemical structures (among them biologically active compounds can be found) could be useful for algae taxonomic studies.

Author Contributions: I.J., M.R. and S.J. made conceptualization of the manuscript. M.K. and Z.M. performed the extractions and analyses of the samples by gas chromatography and mass spectrometry. I.J. elaborated the obtained data. Writing of the manuscript draft was done by I.J. and the manuscript draft was review and edited by S.J. and M.R. Funding acquisition was obtained by I.J.

Funding: This research was funded by the Croatian Government and the European Union through the European Regional Development Fund - the Competitiveness and Cohesion Operational Programme (KK.01.1.1.01) The Scientific Centre of Excellence for Marine Bioprospecting-BioProCro.

Acknowledgments: We would like to thank Croatian Government and the European Union through the European Regional Development Fund-the Competitiveness and Cohesion Operational Programme (KK.01.1.1.01) for funding The Scientific Centre of Excellence for Marine Bioprospecting-BioProCro and this research.

Conflicts of Interest: The authors declare no conflict of interest.

\section{References}

1. Shanura Fernando, L.P.; Nah, J.; Jeon, Y. Potential anti-inflammatory natural products from marine algae. Environ. Toxicol. Pharmacol. 2016, 48, 22-30. [CrossRef] [PubMed]

2. Gonzalez, A.G.; Darias, J.; Martin, J.D. Taondiol, a new component from Taonia atomaria. Tetrahedron Lett. 1971, 12, 2729-2732. [CrossRef]

3. Gonzalez, A.G.; Darias, J.; Martin, J.D.; Norte, M. Atomaric acid, a new component from Taonia atomaria. Tetrahedron Lett 1974, 15, 3951-3954. [CrossRef]

4. Gonzalez, A.G.; Martin, I.D.; Perez, C.; Rovirosa, J.; Tagle, P.B.; Clardy, J. Isolation and x-ray structural determination of three new diterpenoids from the marine alga Taonia atomaria. Chem. Lett. 1984, 13, 1649-1652. [CrossRef]

5. De Rosa, S.; De Giulio, A.; Iodice, C.; Zavodink, N. Sesquiterpenes from the brown alga Taonia atomaria. Phytochemistry 1994, 37, 1327-1330. [CrossRef]

6. Abatis, D.; Vagias, C.; Galanakis, D.; Norris, J.N.; Moreau, D.; Roussakis, C.; Roussis, V. Atomarianones A and B: Two cytotoxic meroditerpenes from the brown alga Taonia atomaria. Tetrahedron Lett. 2005, 46, 8525-8529. [CrossRef]

7. Tziveleka, L.-A.; Abatis, D.; Paulus, K.; Bauer, R.; Vagiasa, C.; Roussis, V. Marine polyprenylated hydroquinones, quinones, and chromenols with inhibitory effects on leukotriene formation. Chem. Biodivers. 2005, 2, 901-909. [CrossRef]

8. El Baz, F.K.; El Baroty, G.S.; Abd El Baky, H.H.; Abd El-Salam, O.I.; Ibrahim, E.A. Structural characterization and biological activity of sulfolipids from selected marine algae. Grasas Aceites 2013, 64, 561-571. 
9. Mayer, A.M.S.; Lehmann, V.K.B. Marine Pharmacology in 1998: Marine compounds with antibacterial, anticoagulant, anti-inflammatory, anthelmintic, antiplatelet, antiprotozoan, and antiviral activities; with actions on the cardiovascular, endocrine, immune, and nervous systems; and other miscellaneous mechanisms of action. Pharmacologist 2000, 42, 62-69.

10. Jacobs, R.S.; Culver, P.; Langdon, R.; O’Brien, E.T.; White, S. Some pharmacological observations on marine natural products. Tetrahedron 1985, 41, 981-984. [CrossRef]

11. Wessels, M.; Konig, G.M.; Wright, A.D. A new tyrosine kinase inhibitor from the marine brown alga Stypopodium zonale. J. Nat. Prod. 1999, 62, 927-930. [CrossRef] [PubMed]

12. Gerwick, W.H.; Fenical, W. Ichthyotoxic and cytotoxic metabolites of the tropical brown alga Stypopodium zonale (Lamouroux) Papenfuss. J. Org. Chem. 1981, 46, 22-27. [CrossRef]

13. Nahas, R.; Abatis, D.; Anagnostopoulou, M.A.; Kefalas, P.; Vagias, C.; Roussis, V. Radical-scavenging activity of Aegean Sea marine algae. Food Chem. 2007, 102, 577-581. [CrossRef]

14. Othmani, A.; Briand, J.-F.; Ayé, M.; Molmeret, M.; Culioli, G. Surface metabolites of the brown alga Taonia atomaria have the ability to regulate epibiosis. Biofouling 2016, 32, 801-813. [CrossRef] [PubMed]

15. Khafaji, A.K. Alginate and laminarin of some brown algae from Red Sea near Jeddah, Saudi Arabia. Pak. J. Bot. 1986, 18, 351-353.

16. Hegazi, M.M.; Perez-Ruzafa, A.; Almela, L.; Candela, M.-E. Separation and identification of chlorophylls and carotenoids from Caulerpa prolifera, Jania rubens and Padina pavonica by reversed-phase high-performance liquid chromatography. J. Chromatogr. A 1998, 829, 153-159. [CrossRef]

17. Kamenarska, Z.; Gasic, M.J.; Zlatovic, M.; Rasovic, A.; Sladic, D.; Kljajic, Z.; Stefanov, K.; Seizova, K.; Najdenski, H.; Kujumgiev, A.; et al. Chemical Composition of the Brown Alga Padina pavonia (L.) Gaill. from the Adriatic Sea. Bot. Mar. 2002, 45, 339-345. [CrossRef]

18. Ibtissam, C.; Hassane, R.; José, M.-L.; Francisco, D.S.J.; Antonio, G.V.J.; Hassan, B.; Mohamed, K. Screening of antibacterial activity in marine green and brown macroalgae from the coast of Morocco. Afr. J. Biotechnol. 2009, 8, 1258-1262.

19. Sultana, V.; Ehteshamul-Haque, S.; Ara, J.; Athar, M. Comparative efficacy of brown, green and red seaweeds in the control of root infecting fungi and okra. Int. J. Environ. Sci. Technol. 2005, 2, 129-132. [CrossRef]

20. Khaled, N.; Hiba, M.; Astma, C. Antioxidant and Antifungal activities of Padina pavonica and Sargassum vulgare from the Lebanese Mediterranean Coast. Adv. Environ. Biol. 2012, 6, 42-48.

21. Ktari, L.; Guyot, M. A cytotoxic oxysterol from the marine alga Padina pavonica (L.) Thivy. J. Appl. Phycol. 1999, 11, 511-513. [CrossRef]

22. Awad, N.E.; Selim, M.A.; Metawe, H.M.; Matloub, A.A. Cytotoxic xenicane diterpenes from the brown alga Padina pavonia (L.) Gaill. Phytother. Res. 2008, 22, 1610-1613. [CrossRef] [PubMed]

23. Tringali, C.; Piatelli, M.; Spatafora, C. Sesquiterpenes and geranylgeranylglycerol from the brown algae Taonia lacheana and Taonia atomaria f. ciliata: Their chemotaxonomic significance. Phytochemistry 1995, 40, 827-831. [CrossRef]

24. El Shoubaky, G.A.; Essam, A.; Salem, E.A. Terpenes and sterols composition of marine brown algae Padina pavonica (Dictyotales) and Hormophysa triquetra (Fucales). Int. J. Pharmacogn. Phytochem. Res. 2014, 6, 894-900.

25. Stranden, M.; Borg-Karlson, A.-K.; Mustaparta, H. Receptor neuron discrimination of the germacrene D enantiomers in the moth Helicoverpa armigera. Chem. Senses 2002, 27, 143-152. [CrossRef] [PubMed]

26. Kiran, S.R.; Devi, P.S. Evaluation of mosquitocidal activity of essential oil and sesquiterpenes from leaves of Chloroxylon swietenia DC. Parasitol. Res. 2007, 101, 413-418. [CrossRef] [PubMed]

27. Bruce, T.J.A.; Birkett, M.A.; Blande, J.; Hooper, A.M.; Martin, J.L.; Khambay, B.; Prosser, I.; Smart, L.E.; Wadhams, L.J. Response of economically important aphids to components of Hemizygia petiolata essential oil. Pest. Manag. Sci. 2005, 61, 1115-1121. [CrossRef] [PubMed]

28. Casiglia, S.; Bruno, M.; Bramucci, M.; Quassinti, L.; Lupidi, G.; Fiorini, D.; Maggi, F. Kundmannia sicula (L.) DC: A rich source of germacrene D. J. Essent. Oil Res. 2017, 29, 437-442. [CrossRef]

29. Setzer, W.N.; Schmidt, J.M.; Noletto, J.A.; Vogler, B. Leaf oil compositions and bioactivities of abaco bush medicines. Pharmacologyonline 2006, 3, 794-802.

30. Kuiate, J.-R.; Bessiere, J.M.; Amvam Zollo, P.H.; Philibert Kuate, S. Chemical composition and antidermatophytic properties of volatile fractions of hexanic extract from leaves of Cupressus lusitanica Mill. from Cameroon. J. Ethnopharmacol. 2006, 103, 160-165. [CrossRef] 
31. Bozan, B.; Ozek, T.; Kurkcuoglu, M.; Kirimer, N.; Baser, K.; Husnu, C. Analysis of essential oil and headspace volatiles of the flowers of Pelargonium endlicherianum used as an anthelmintic in folk medicine. Planta Med. 1999, 65, 781-782. [CrossRef]

32. Jerković, I.; Marijanović, Z.; Roje, M.; Kuś, P.M.; Jokić, S.; Čoz-Rakovac, R. Phytochemical study of the headspace volatile organic compounds of fresh algae and seagrass from the Adriatic Sea (single point collection). PLOS ONE 2018, 13, e0196462.

33. Moore, R.E. Volatile compounds from marine algae. Acc. Chem. Res. 1977, 10, 40-47. [CrossRef]

34. Jüttner, F. Biologically active compounds released during algal blooms. Int. Ver. Theor. Angew. 1981, 21, 227-230. [CrossRef]

35. Seymour, J.R.; Simo, R.; Ahmed, T.; Stocker, R. Chemoattraction to dimethylsulfoniopropionate throughout the marine microbial food web. Science 2010, 329, 342-345. [CrossRef] [PubMed]

36. Kim, S.K. Handbook of Marine Macroalgae: Biotechnology and Applied Phycology; John Wiley \& Sons Ltd.: Chichester, UK, 2012.

37. Le Bideau, F.L.; Kousara, L.; Chen, M.; Lai Wei, L.; Dumas, F. Tricyclic sesquiterpenes from marine origin. Chem. Rev. 2017, 117, 6110-6159. [CrossRef] [PubMed]

38. Arinoni, D. Stereochemical aspects of sesquiterpene biosynthesis. Pure Appl. Chem. 1975, 4, $219-245$. [CrossRef]

39. Alcolombri, U.; Ben-Dor, S.; Feldmesser, E.; Levin, Y.; Tawfik, D.S.; Vardi, A. Identification of the algal dimethyl sulfide-releasing enzyme: A missing link in the marine sulfur cycle. Science 2015, 348, 1466-1469. [CrossRef] [PubMed]

40. Hatanaka, A. The biogeneration of green odor by green leaves. Phytochemistry 1993, 34, 1201-1218. [CrossRef]

41. Pohnert, G.; Boland, W. The oxylipin chemistry of attraction and defense in brown algae and diatoms. Nat. Prod. Rep. 2002, 19, 108-122.

42. Hombeck, M.; Boland, W. Biosynthesis of the algal pheromone fucoserratene by the fresh- water diatom Asterionella formosa (Bacillariophyceae). Tetrahedron 1998, 54, 11033-11042. [CrossRef]

43. Tanchotikul, U.; Hsieh, T.C.-Y. Volatile flavor components in crayfish waste. J. Food Sci. 1989, 54, 1515-1520. [CrossRef]

44. National Institute of Standards and Technology (NIST) Chemistry WebBook. NIST Standard Reference Database Number 69. Available online: http:/ / webbook.nist.gov/ chemistry / (accessed on 12 December 2018).

Sample Availability: The samples of the marine algae are available from the authors for limited time.

(C) 2019 by the authors. Licensee MDPI, Basel, Switzerland. This article is an open access article distributed under the terms and conditions of the Creative Commons Attribution (CC BY) license (http:// creativecommons.org/licenses/by/4.0/). 